\title{
A Boundary Delineation System for the Bureau of Ocean Energy Management
}

\author{
Douglas L. Vandegraft ${ }^{\mathrm{a}}$ \\ ${ }^{a}$ Chief, Mapping and Boundary Branch, Bureau of Ocean Energy Management, 45600 Woodland Road, VAM-LD, Sterling, VA \\ 20166,Doug.Vandegraft@boem.gov
}

\begin{abstract}
Federal government mapping of the offshore areas of the United States in support of the development of oil and gas resources began in 1954. The first mapping system utilized a network of rectangular blocks defined by State Plane coordinates which was later revised to utilize the Universal Transverse Mercator grid. Creation of offshore boundaries directed by the Submerged Lands Act and Outer Continental Shelf Lands Act were mathematically determined using early computer programs that performed the required computations, but required many steps. The Bureau of Ocean Energy Management has revised these antiquated methods using GIS technology which provide the required accuracy and produce the mapping products needed for leasing of energy resources, including renewable energy projects, on the outer continental shelf. (Note: this is an updated version of a paper of the same title written and published in 2015).
\end{abstract}

Keywords: Outer Continental Shelf, Marine (Offshore) Cadastre, Submerged Lands Act, Of-ficial Protraction Diagram, Supplemental Official Block Diagram

\section{Introduction}

The Bureau of Ocean Energy Management, formerly the Minerals Management Service, is the bureau within the U.S. Department of the Interior that is responsible for the exploration and development of energy and marine mineral re-sources on the Outer Continental Shelf of the United States. This includes the leasing of the mineral resources of the seabed of the Outer Continental Shelf. The Outer Continental Shelf is defined by the Outer Continental Shelf Lands Act as all submerged lands lying seaward and outside of the area of lands beneath navigable waters... and of which the subsoil and seabed appertain to the United States and are subject to its jurisdiction and control.

Under the general authority of the Outer Continental Shelf Lands Act, the Department of the Interior has the primary responsibility for administering the official marine (offshore) cadastre for the United States. The marine cadastre ex-tends from the official baseline of the nation's coastline to the full extent of the Outer Continental Shelf, which in most areas is coincident with the boundary of the Exclusive Economic Zone, lying 200 nautical miles seaward from the base-line. The marine cadastre is a comprehensive spatial data mapping infrastructure whereby rights, restrictions and responsibilities in the marine environment can be assessed, administered and managed. The marine cadastre includes the block grids and official boundaries, which provide the base for nearly all of the Bureau of Ocean Energy Management offshore maps and leasing processes. It also gives the Bureau of Ocean Energy Management the means to define, describe, analyze, and account for every acre/hectare of federal offshore submerged lands.

\section{Background}

Prior to the creation of the Minerals Management Service in 1982, the map-ping of offshore oil and gas areas was the responsibility of the Bureau of Land Management. In 1954, the Bureau of Land Management published the first Leasing Maps and issued the first leases offshore of Texas and Louisiana. These first Leasing (or Lease) Maps were based on the local State Plane Coordinate Sys-tem for those states. A typical Outer Continental Shelf Block contained 5000 acres, with the block grid beginning at the coast line.

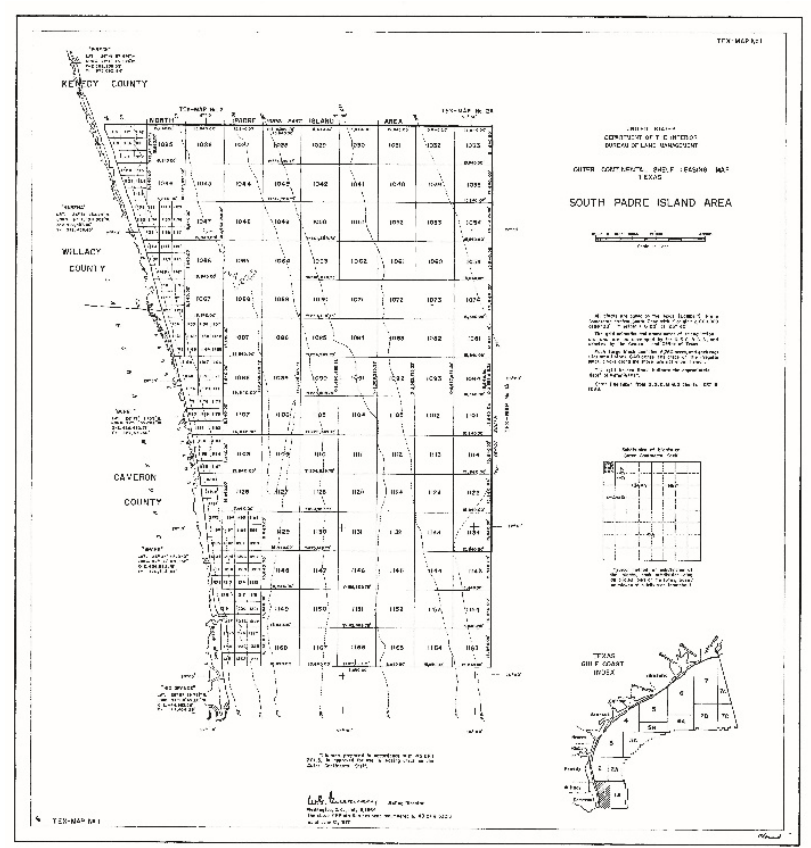


Fig. 1. Leasing Map showing the Outer Continental Shelf blocks offshore of South Padre Is-land, Texas. Map published by the Bureau of Land Management in 1954.

The Submerged Lands Act was passed by Congress in 1953. For coastal states, this meant title and ownership of submerged lands within three nautical miles from their coast line (except nine nautical miles for Texas and the Gulf Coast of Florida). The Submerged Lands Act boundary is projected seaward from officially recognized baseline points along the mean lower low water line of the coast. In 1963, Lease Maps were produced that reflected the Submerged Lands Act boundary offshore of Oregon. On these maps, the block grid began at the Submerged Lands Act boundary, which officially divides State and Federal submerged lands.

In 1967, the Bureau of Land Management decided to utilize the Universal Transverse Mercator (UTM) grid system for the first Lease Maps generated for the Gulf of Alaska. This decision was made because of the limitations of the State Plane Coordinate System as coordinates were extended further from the coast line. However, the drawing of the Submerged Lands Act boundary remained on a planar (flat) trajectory from the coastal baseline points, as opposed to using a geodesic (curved) trajectory. It was important to retain this consistency because of active leases on many of the existing Lease Maps where the State Plane Coordinate System had been used and the Submerged Lands Act boundary drawn.

In the 1970's, the Bureau of Land Management developed mapping computational software based on the FORTRAN programming language to create the marine cadastre. While revolutionary at the time, the software is manually intensive and requires days and sometimes months to perform tasks such as projecting boundaries and creating block grids. Limitations of the software include the inability to project a line seaward beyond 12 nautical miles or to generate blocks and boundaries in the Southern Hemisphere or west of $180^{\circ}$.

In 1974, the Bureau of Land Management created the first Official Protraction Diagrams offshore of New Jersey and Maine. The Official Protraction Diagrams utilized the UTM grid, which increased the size of the blocks to 5760 acres. A standard Official Protraction Diagram measures $1^{\circ}$ in latitude by $2^{\circ}$ in longitude south of $48^{\circ}$ latitude; the size increases to $3^{\circ}$ in longitude north of $48^{\circ}$. Official Protraction Diagrams are intended to be printed at a scale factor of 1:250,000. While diagrams illustrating where the Submerged Lands Act boundary passed through an Outer Continental Shelf block had been created as early as 1957, the format for the Supplemental Official Block Diagram was not developed until 1980. Supplemental Official Block Diagrams are generated for all Outer Continental Shelf blocks (and only those blocks) which contain a portion of a boundary, such as the Submerged Lands Act boundary. The Supplemental Official Block Diagrams reflect information about the type of boundary (or boundaries) within the Outer Continental Shelf block, intersection coordinate values for where the boundary enters and exits the block, arc and tangent segments projected off-shore from the baseline, and the arc centers (the contributing baseline points).

In 1978, the Outer Continental Shelf Lands Act was amended. Section $8(\mathrm{~g})$ identified an area between three and six nautical miles offshore (or nine and twelve nautical miles where applicable), referred to as the ' $8(\mathrm{~g})$ Zone.' Revenues obtained from leases located inside the 8(g) Zone would be shared between the adjacent coastal state and the Federal government. In 1986, Section $8(\mathrm{~g})$ was amended to specify that the coastal state would receive $27 \%$ of the revenues generated. The $8(\mathrm{~g})$ Zone boundary began appearing on Lease Maps, Official Protraction Diagrams, and Supplemental Official Block Diagrams in the early 1980's.

In 1982, the Minerals Management Service was created, and the following year, a new mapping datum was implemented for North America. In 1989, all Federal agencies that performed mapping activities were instructed to migrate to the North American Datum of 1983 (NAD83). By this time, there were over 5000 active leases in the Gulf of Mexico. A plan was devised for the Minerals Management Service to convert all maps from the North American Datum of 1927 (NAD27) to NAD83. However, the conversion was completed for all regions except the Gulf of Mexico. The Bureau of Ocean Energy Management still uses NAD27 for mapping in the Gulf of Mexico.

In 1992, the Technical Information Management System was developed by the Minerals Management Service. The Technical Information Management System database contains all of the major business functions required for the Bureau of Ocean Energy Management to perform leasing activities. All of the map-ping tools and tabular data, such as block and boundary coordinates, are stored in the Block and Boundary component of this system. The Technical Information Management System was originally designed using client-server technology, and although it has evolved into a browser-based model, it has reached limitations for further evolution. Geospatial data cannot be stored within the current configuration of the Technical Information Management System, and the map-ping tools are not functional outside of North America.

\section{Building a new system}

In 2007, efforts began to replace the Technical Information Management Sys-tem mapping tools with a new system that utilized Geographic Information Sys-tem (GIS) technology. The initial plans were to have custom tools developed that would perform all of the necessary calculations, generate blocks and boundaries, and produce maps. Contracts with Environmental Systems Research Institute, Inc. (Esri) to develop these custom tools were signed in 2009 and 2010, and the first set of Boundary Delineation Tools was delivered in 2010.

An important issue was the projection of the offshore boundaries from the coastal baseline points. Offshore boundary lines are measured along an arc over the earth's 
ellipsoidal surface (known as the chord length); therefore, chord length varies with latitude and azimuth according to variations in the radius of the earth's surface. As a result, the arc must be computed separately for each stretch of coastline, even though the projection distance remains unchanged for a particular boundary. At that time, the 'Buffer' command in the ArcGIS suite of mapping tools did not take into account chord length or distortion due to projection and often resulted in an inaccurate representation of an arc. Esri delivered a custom tool for the projection of boundaries (known as Project Boundary) which had the option to generate a boundary on a planar projection (a planar line) or on a geodesic projection (a geodesic line). The tool was tested by the Bureau of Ocean Energy Management and determined to need improvements.

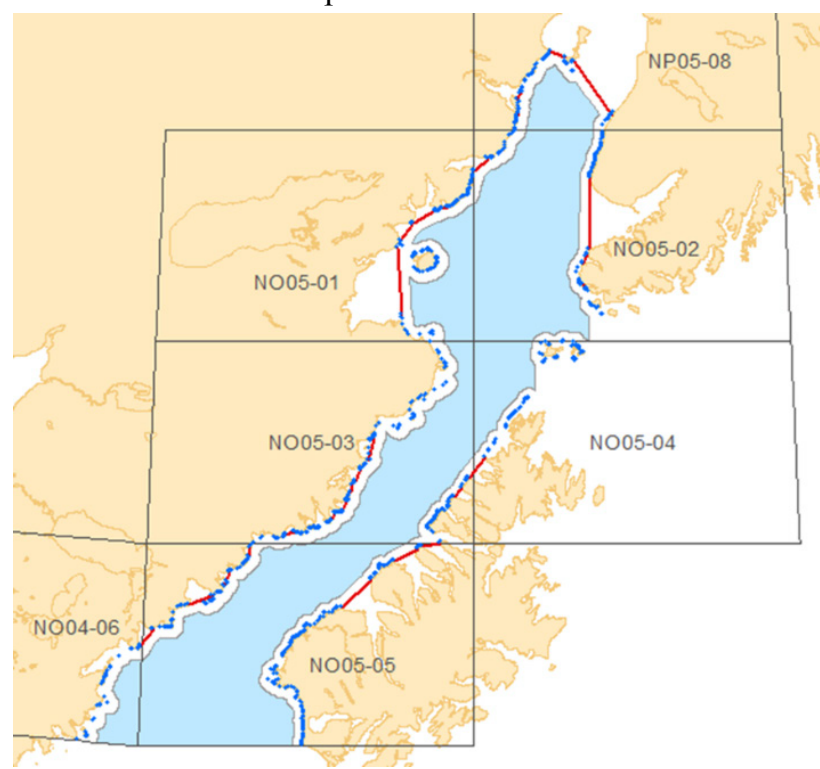

Fig. 2. The baseline points (blue) and bay closing lines (red) are used to project the Sub-merged Lands Act boundary, which lies three nautical miles seaward of the coast line. This area of Cook Inlet, Alaska, requires seven Official Protraction Diagrams (grid shown).

In 2010, after the Deepwater Horizon oil spill in the Gulf of Mexico, the Minerals Management Service was renamed the Bureau of Ocean Energy Management, Regulation, and Enforcement. In 2011, the reorganization process divided the Bureau of Ocean Energy Management, Regulation, and Enforcement into three separate bureaus: the Bureau of Ocean Energy Management; the Bureau of Safety and Environmental Enforcement; and the Office of Natural Resource Revenue. The marine cadastre mapping responsibilities remained with the Bureau of Ocean Energy Management. In 2011, the Pacific Region of the Bureau of Ocean Energy Management re-quested that official mapping products be developed for the principal islands of Hawaii in support of proposed renewable energy projects. The Bureau of Ocean Energy Management began negotiating a new contract with Esri to resolve issues with the existing custom tools and to produce the requested maps. Subsequently, an extended timeline for the energy projects for Hawaii allowed the Bureau of Ocean Energy
Management to take a broader-scope approach for developing a new system that would work in all geographic areas of the United States.

In 2014, the Bureau of Ocean Energy Management began the development of the Boundary Delineation System to support a transition from the Technical In-formation Management System tools to a graphic user interface (GUI). The new Data Model was designed to service all areas of the United States including its territories and possessions. The Atlantic, Pacific (California, Oregon, and Washing-ton), and the Alaska Regions utilize the NAD83, while Hawaii and the other Pacific Ocean areas are being mapped using the World Geodetic System of 1984 (WGS84) datum. The Gulf of Mexico will remain on the NAD27. All of the Regions will migrate to a new datum when the National Spatial Reference System is updated in 2022.

Because the Technical Information Management System is still the principal database utilized by the Bureau of Ocean Energy Management, the Bureau of Safe-ty and Environmental Enforcement, and the Office of Natural Resource Revenue, a primary requirement of the contract was that data be transferred between the Technical Information Management System and the Boundary Delineation System. Data Interoperability, an ArcGIS extension for data access and translation, is being used for the data import and export. During the process, tools that extract, transform, and load the data (known as ETL tools) are built and used for data validation, migration, and distribution.

The new Data Model utilizes multiple geodatabases to store the block and boundary data. The geodatabases are based on individual zones of the UTM projection. Storing the data in geodatabases, which is a common Esri format, ensures that the data can be imported and exported between the Boundary Delineation System and other GIS applications and/or report systems. A total of forty-two (42) geodatabases will be constructed to accurately map all Outer Continental Shelf areas of the United States.

Another requirement written into the contract was that only commercial-off-the-shelf (COTS) tools found in ArcGIS be used to perform all of the mapping and data transformation processes. 


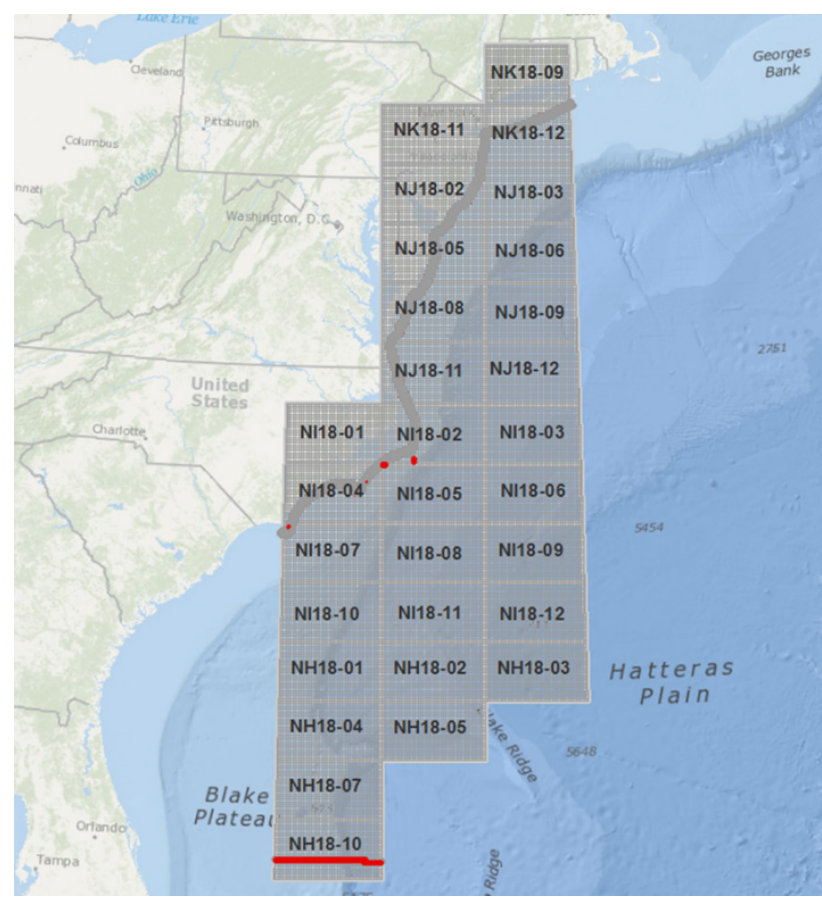

Fig. 3. The Boundary Delineation System utilizes geodatabases that are based on individual zones of the Universal Transverse Mercator (UTM) projection. Shown here are the Official Protraction Diagrams within the geodatabase for UTM Zone 18 North in the Atlantic Region.

Call Order \#1 of the contract with Esri was initiated in January 2015. Received from Esri was a "proof of concept" for the Boundary Delineation System project, which included documentation of the Data Model; the proposal for import of the block and boundary data for the Atlantic, Pacific, and Alaska Regions from the Technical Information Management System into the Boundary Delineation Sys-tem; the review, validation, and workflow processes for using the COTS tools for the generation of new blocks and boundaries; and a recommendation report for future map production, which included templates for a revised design of the Official Protraction Diagram and Supplemental Official Protraction Diagram. Be-cause leases for renewable energy projects can be issued for Outer Continental Shelf blocks that have been subdivided in sixteen aliquot parts, two new map products will be developed: the Official Protraction Aliquot Diagram and the Supplemental Official Aliquot Diagram.

Call Order \#2 was initiated in October 2015. Received from Esri was a total of nineteen (19) separate geodatabases that utilize the NAD83. Block and boundary data from the Technical Information Management System for the Atlantic, Pacific, and Alaska Regions was successfully imported into the NAD83 geodatabases with a $98 \%$ accuracy rate. This required that the Bureau of Ocean Energy Management perform quality control checks to identify the data gaps. Esri was also able to export the data back into the Technical Information Management System, proving that any new data generated in the Boundary Delineation Sys-tem could be shared between the two systems. Also generated were two (2) geo-databases based on the UTM projection in the WGS84 datum. These geodatabases are being used to store Outer Continental Shelf blocks, coastal baselines, boundaries, and other data for the principal islands of Hawaii. Also provided was documentation for all of the workflow processes.

Based on previous contract work done for the Bureau of Ocean Energy Management, Esri made adjustments to the COTS "Buffer" tool. The tool now creates true circular arcs, and has an option to create buffers on a planar or geodesic trajectory. As part of the Boundary Delineation System workflow to generate an offshore boundary, the Bureau of Ocean Energy Management creates a planar buffer from the coastal baseline points, converts the buffer polygon rings to lines, planarizes the lines, and deletes that portion of the resulting buffer that is created on the landward side.

Call Order \#3 was initiated in March 2017. Esri is importing the block and boundary data from the Technical Information Management System for the Gulf of Mexico Region (which utilizes the NAD27) into the Boundary Delineation Sys-tem. Three (3) geodatabases are based on the State Plane Coordinate System, and four (4) are based on the UTM projection, for a total of seven (7) geodatabases generated. All of the current ("active") data will be imported which reflects those Outer Continental Shelf blocks and boundaries that are shown on present-day Bureau of Ocean Energy Management maps and used in lease sales. In the Gulf of Mexico Region, the Bureau of Ocean Energy Management has the need to utilize "historical" data for the purposes of comparing legacy boundaries, base-lines, and area calculations. To fulfill this requirement, Esri will import historical data for one (1) Official Protraction Diagram, and one (1) Lease Map. Esri will al-so provide to the Bureau of Ocean Energy Management the ETL processes that perform the import of the historical data from the Technical Information Management System into the Boundary Delineation System. Having this documentation will allow the Bureau of Ocean Energy Management to replicate this action for other Official Protraction Diagrams and Lease Maps in the future.

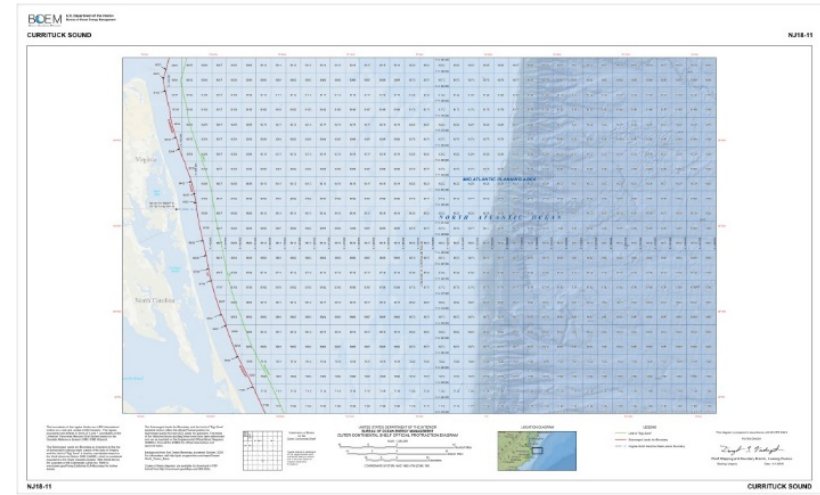

Fig. 4. The Bureau of Ocean Energy Management is now using the Esri Oceans basemap for Official Protraction Diagrams. Shown here is the Currituck Sound Official Protraction Diagram in the Atlantic Region. 


\section{Conclusion}

After ten years, the efforts to replace the antiquated Technical Information Management System mapping tools utilized by the Minerals Management Service have finally paid off. The Bureau of Ocean Energy Management now has the databases and tools needed to efficiently generate accurate marine boundaries, and a map production system that will quickly provide the products required for energy development on the Outer Continental Shelf.

\section{References}

Outer Continental Shelf Lands Act (1953). Public Law 212, 83rd Congress, 1st Session; 67 Stat. 462, 43 U.S.C. 1331

Submerged Lands Act (1953). Public Law 31, 83rd Congress, 1st Session; 67 Stat. 29; 43 U.S.C. 1301

Thormahlen, L (1999) Boundary Development on the Outer Continental Shelf. OCS Report MMS 99-0006. U.S. Department of the Interior, Minerals Management Service, Washing-ton, D.C. 